\title{
Paradoxical counteraction by imatinib against cell death in myeloid progenitor 32D cells expressing p210BCR-ABL
}

\author{
Morichika Takita ${ }^{1, *}$, Fujiko Tsukahara ${ }^{1, *}{ }^{,}$Taishi Mishima ${ }^{1}$, Katsuaki Ieguchi ${ }^{1}$, \\ Masayuki Yamada ${ }^{1,2}$, Hiroaki Honda ${ }^{3}$ and Yoshiro Maru ${ }^{1}$ \\ ${ }^{1}$ Department of Pharmacology, Tokyo Women's Medical University, Tokyo, Japan \\ ${ }^{2}$ Center for Medical Education, Graduate School of Medicine, Kyoto University, Kyoto, Japan \\ ${ }^{3}$ Institute of Laboratory Animals, Tokyo Women's Medical University, Tokyo, Japan \\ *These authors have contributed equally to this work \\ Correspondence to: Morichika Takita, email: mtakita@twmu.ac.jp \\ Yoshiro Maru, email: maru.yoshiro@twmu.ac.jp \\ Keywords: chronic myeloid leukemia; p210BCR-ABL; Imatinib; cell death; differentiation \\ Received: February 06, $2018 \quad$ Accepted: July 12, $2018 \quad$ Published: August 03, 2018 \\ Copyright: Takita et al. This is an open-access article distributed under the terms of the Creative Commons Attribution License 3.0 \\ (CC BY 3.0), which permits unrestricted use, distribution, and reproduction in any medium, provided the original author and source \\ are credited.
}

\section{ABSTRACT}

Chronic myeloid leukemia (CML) is believed to be caused by the tyrosine kinase P210BCR-ABL, which exhibits growth-promoting and anti-apoptotic activities. However, mechanisms that allow cell differentiation in CML still remain elusive. Here we established tetracycline (Tet)-regulatable p210BCR-ABL-expressing murine 32D myeloid progenitor (32D/TetOff-p210) cells to explore p210BCR-ABL-induced cell death and differentiation. Tet-regulatable overexpression of p210BCR-ABL induced cell death due to the activation of both caspase-1 and caspase-3, coincident with the differentiation from myeloid progenitors into CD11 $b^{+}$Ly6C $C^{+}$Ly6G $G^{+}$cells with segmented nuclei, exemplified as granulocytic myeloid-derived suppressor cells (G-MDSC), and the ability to secrete IL-1 $\beta$, TNF-a, and S100A8/A9 into the culture supernatant. Treatment with imatinib almost completely abrogated all these phenotypes. Moreover, overexpression of a sensor of activated caspase-1 based on fluorescence resonance energy transfer (FRET) probe enabled us to detect activation of caspase-1 in a human CML cell line, K562. Furthermore, increased numbers of splenic G-MDSC associated with enhancement of S100A8/A9 production were observed in transgenic mice expressing P210BCR-ABL compared with that in wild-type mice. We also propose the novel mode of cell death in this 32D/TetOff-p210 system termed as myeloptosis.

\section{INTRODUCTION}

Chronic myeloid leukemia (CML) is a hematopoietic malignant disease caused by the tyrosine kinase $\mathrm{p} 210 \mathrm{BCR}-\mathrm{ABL}$. Although the most characteristic manifestation of CML is the lack of a differentiation block in leukemic cells, there has been almost no biological system in which cell differentiation followed by cell death occurs in a p210BCR-ABL-dependent manner [1-4]. A previous study has shown that interleukin-1 $\beta$ $(\mathrm{IL}-1 \beta)$ is elevated in the bone marrow of BCR-ABL transgenic (TG) SCL-tTa/BCR-ABL mice [5], but the precise mechanism and the biological significance of BCR-ABL-induced IL-1 $\beta$ elevation is unclear. Caspase-1 was originally identified as an IL-1 $\beta$ converting enzyme, which converts proIL-1 $\beta$ to active IL-1 $\beta$ [6]. Multiprotein complexes called inflammasomes, such as NLRP3 (Nodlike receptor family, pyrin domain containing 3), are required for caspase-1 activation [7]. Caspase-1-induced cell death is called pyroptosis, and is accompanied by the secretion of proinflammatory cytokines, such as IL-1 $\beta$ and IL-18 [8]. Although detection of activated caspase-1 is often difficult, a sensor of activated caspase-1 based on fluorescence resonance energy transfer (FRET) probe 
(SCAT1) has recently been developed and shown to be highly sensitive and specific to visualize caspase-1 activity even in a single cell [9].

Myeloid derived suppressor cells (MDSC) suppress immune responses against tumor antigens and promote cancer metastasis [10]. MDSC possess potent immune suppressor functions as initially described in tumor-bearing mice models [11]. Murine MDSC are subdivided into granulocytic MDSC (G-MDSC; CD11b ${ }^{+}$Ly6C ${ }^{\text {low }} \mathrm{Ly}_{6 \mathrm{G}^{+}}$cells) and monocytic MDSC (M-MDSC; CD11b ${ }^{+}$Ly6C ${ }^{\text {high }}$ Ly6G $^{-}$cells), and human MDSC are subdivided into G-MDSC $\left(\mathrm{CD} 11 \mathrm{~b}^{+} \mathrm{CD} 33^{+} \mathrm{HLA}-\right.$ $\mathrm{DR}^{\text {neg/low }}{ }^{-} \mathrm{D} 14^{-}$cells $)$and M-MDSC $\left(\mathrm{CD} 11 \mathrm{~b}^{+} \mathrm{CD} 33^{+} \mathrm{HLA}-\right.$ $\mathrm{DR}^{\text {neg/low }} \mathrm{CD}^{+} 4^{+}$cells) [10]. A recent clinical study has shown that G-MDSC numbers were increased significantly in Sokal high risk patients with CML compared with those in control subjects [12].

Tyrosine kinase activities are required for cell proliferation and differentiation. A previous study has shown that retroviral expression of $\mathrm{v}$-src induces neuronal differentiation in the culture system of PC12 rat phaeochromocytoma cells [13]. Furthermore, retroviral infection with p210BCR-ABL in bone marrow-derived multipotent hematopoietic progenitors stimulates cell growth and differentiation into mast cells, macrophages, granulocytes, and B lymphoids in the soft agar colony assay [1].

In the present study, we established tetracycline (Tet)-regulatable p210BCR-ABL-expressing 32D myeloid progenitor (32D/TetOff-p210) cells of murine origin to explore p210BCR-ABL-induced cell death and differentiation. We found that Tet-regulatable overexpression of p210BCR-ABL-induced cell death was caused by caspase- 1 and -3 activations, coincident with the differentiation from myeloid progenitors into G-MDSC and the secretion of IL- $1 \beta$, tumor necrosis factor- $\alpha(\mathrm{TNF}-\alpha)$, and S100A8/A9 in 32D/TetOff-p210 cells. Furthermore, increased numbers of G-MDSC associated with enhancement of S100A8/A9 production were observed in TG mice expressing p210BCR-ABL compared with those in wild-type (WT) mice. Here we propose a novel mode of cell death, termed as myeloptosis, induced by Tet-regulatable overexpression of $\mathrm{p} 210 \mathrm{BCR}$ $\mathrm{ABL}$ in $32 \mathrm{D} /$ TetOff-p210 cells.

\section{RESULTS}

\section{Influence of p210BCR-ABL overexpression on caspase-1 activation}

To clarify the involvement of p210BCR-ABL in caspase-1 activation, we first induced overexpression of both p210BCR-ABL and SCAT1 [9], and monitored SCAT1 cleavage in HeLa cells. Because SCAT1 harbors the caspase-1 cleavage site YVAD in the linker region, it can be recognized by activated caspase- 1 and its cleavage reflects caspase-1 activation [9]. SCAT1 was detected as a full-length form, an approximately $50-\mathrm{kDa}$ band probed with anti-Myc antibody, in HeLa cells transfected only with SCAT1 cDNA (Figure 1A, lane 2). When the cells were treated with a combination of cycloheximide and TNF- $\alpha$ (CHX/TNF), which can induce caspase activation and cell death [14], the cleaved SCAT1 was detected as an approximately $27-\mathrm{kDa}$ band (Figure 1A, lane 3). The co-expression of Flag-tagged wild type p210BCRABL (p210-Flag) and SCAT1 weakly but substantially promoted SCAT1 cleavage, which was enhanced by 9.2fold when additionally treated with $\mathrm{CHX} / \mathrm{TNF}$ (Figure $1 \mathrm{~A}$, lanes 4 and 5). Treatment with a caspase-1 specific inhibitor, z-YVAD-fmk, inhibited the SCAT1 cleavage in cells co-transfected with SCAT1 and p210-Flag in the presence or absence of $\mathrm{CHX} / \mathrm{TNF}$ (Figure 1B, lanes 6 vs 7 , lanes 8 vs 9). Treatment with a BCR-ABL tyrosine kinase inhibitor, imatinib, inhibited both SCAT1 cleavage and tyrosine phosphorylation of p210-Flag (Figure 1C, lanes 4 vs 5). Furthermore, we could barely detect SCAT1 cleavage in cells transfected with a Flag-tagged kinasedead mutant of p210BCR-ABL (p210KD-Flag) compared with the p210-Flag (Figure 1C, lanes 4 vs 6). These results suggest p210BCR-ABL-induced SCAT1 cleavage is dependent on both activities of BCR-ABL tyrosine kinase and caspase- 1 .

To demonstrate p210BCR-ABL-induced caspase-1 activation in a CML cell line, we subsequently tested whether SCAT1 cleavage can be detected in K562, a human CML cell line, which constitutively expresses p210BCR-ABL. SCAT1 cleavage was observed in whole cell lysate (WCL) and in the cell culture supernatant of K562 cells transfected with SCAT1 cDNA (Figure 1D, lanes 2 and 4). These results suggest p210BCR-ABL likely induces caspase- 1 activation in K562 cells.

\section{Establishment of Tet-regulatable p210BCR-ABL- expressing mouse myeloid progenitor 32D cells}

Having shown that p210BCR-ABL potentially activated caspase-1 in a CML cell line (Figure 1D), we then established a Tet-regulatable p210BCR-ABL-expressing mouse myeloid cell line using the method previously reported $[15,16]$. Because a previous study has shown that mouse myeloid progenitor 32D cells differentiate into granulocytes by treatment with granulocyte-colony stimulation factor (G-CSF) [17], we selected 32D cells to establish Tet-depletion-induced p210BCR-ABLexpressing (32D/TetOff-p210) cells and examined p210BCR-ABL-induced cell death and differentiation. p210BCR-ABL protein was induced by 10 -fold under Tet-depletion (Figure 2A, lanes 1 vs 2). Treatment with imatinib decreased tyrosine-phosphorylated p210BCRABL but not total p210BCR-ABL protein amounts in 32D/TetOff-p210 cells (Figure 2A, lanes 2 vs 3). Leaky expression of $\mathrm{p} 210 \mathrm{BCR}-\mathrm{ABL}$ protein was also detected 
in the presence of Tet (Figure 2A, lane1). The level of p210BCR-ABL protein in Tet-depleted 32D/TetOff-p210 cells was 7-fold higher than that of $\mathrm{Ba} / \mathrm{F} 3$ cells stably expressing p210-Flag (Supplementary Figure 1). IL-3 supplement was required for cell growth in parental 32D cells but not in 32D/TetOff-p210 cells because leaky expression of $\mathrm{p} 210 \mathrm{BCR}-\mathrm{ABL}$ contributed to cell growth.

\section{Effect of Tet-regulatable overexpression of p210BCR-ABL on cell viability and cell death in 32D/TetOff-p210 cells}

To examine the influence of Tet-regulatable overexpression of p210BCR-ABL on cell growth, we performed mitochondrion dehydrogenase-based
A

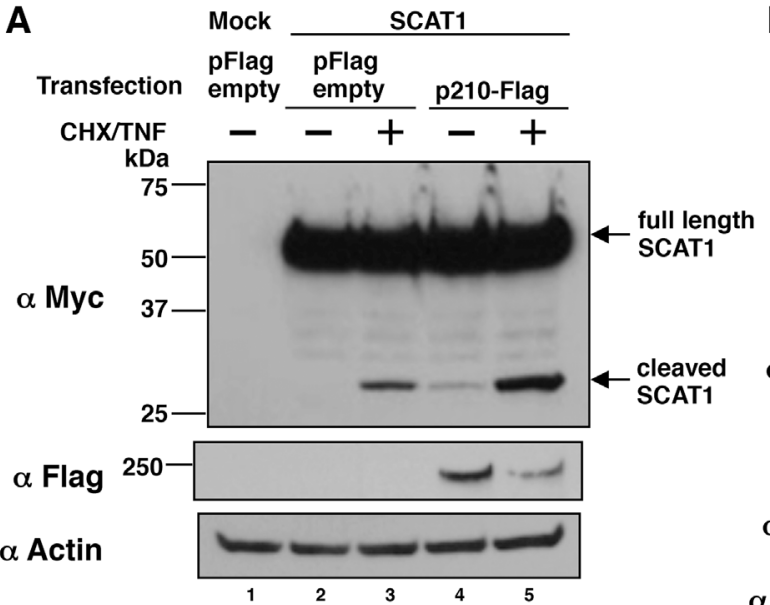

B
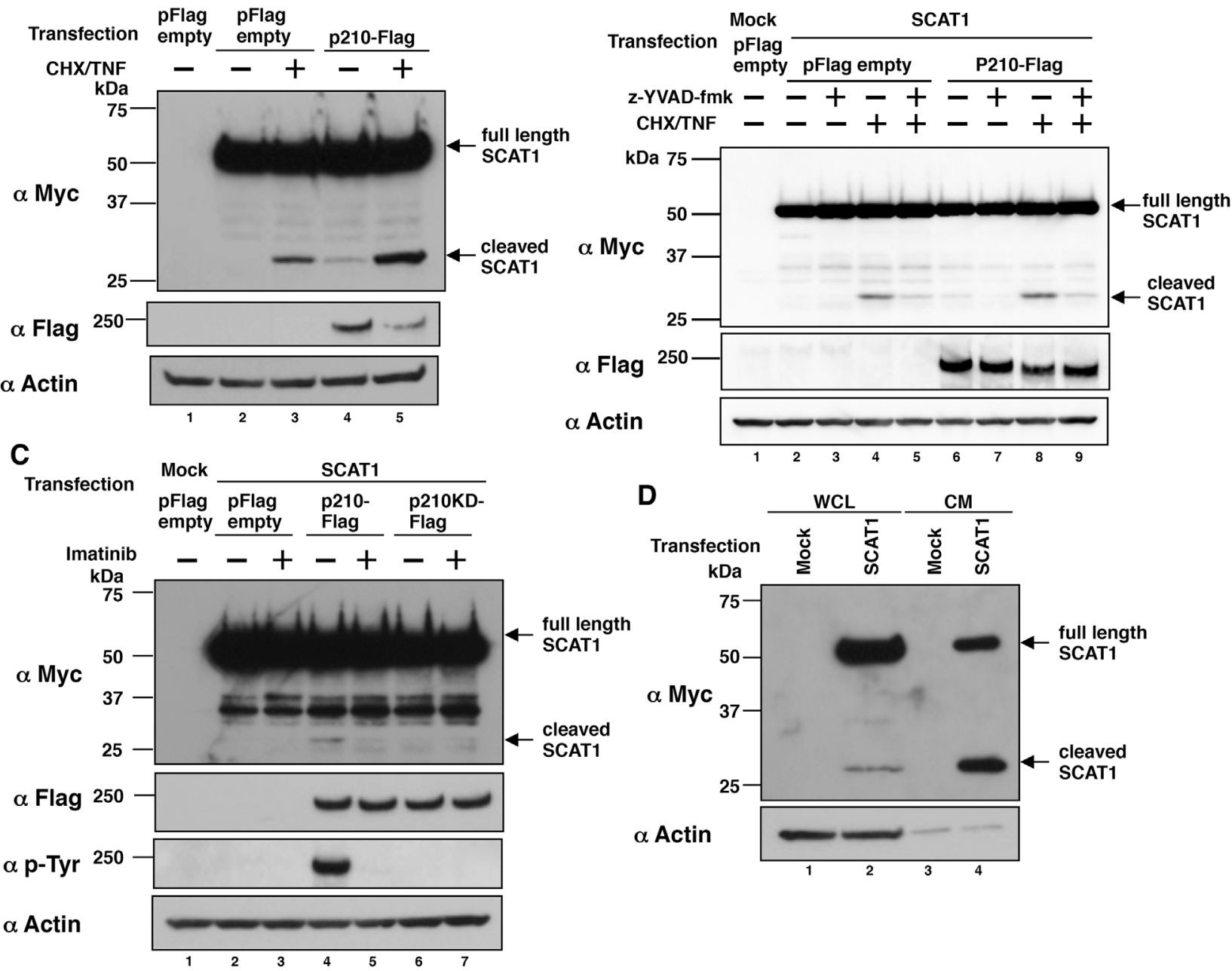

Figure 1: p210BCR-ABL-induced SCAT1 cleavage is dependent on both activities of BCR-ABL tyrosine kinase and caspase-1. (A) HeLa cells were transiently transfected with SCAT1 and Flag-tagged p210BCR-ABL (p210-Flag). At 43 h after transfection, cells were washed with PBS and then treated with serum-free DMEM in the presence or absence of TNF- $\alpha$ (50 ng/ml) and cycloheximide $(\mathrm{CHX})(10 \mu \mathrm{g} / \mathrm{ml})$ for $5 \mathrm{~h}$. WCL were prepared and subjected to immunoblotting. Bands were visualized by probing with antibodies against Myc tag or Flag tag or actin. (B) HeLa cells were transiently transfected with SCAT1 and p210-Flag or pFlag empty vector. At 24 h after transfection, z-YVAD-fmk $(20 \mu \mathrm{M})$ was added and further cultured for $19 \mathrm{~h}$; cells were washed with PBS and then treated with serum-free DMEM with or without z-YVAD-fmk $(20 \mu \mathrm{M})$ and/or TNF- $\alpha(50 \mathrm{ng} / \mathrm{ml})$ and cycloheximide $(10 \mu \mathrm{g} / \mathrm{ml})$ for $5 \mathrm{~h}$. WCL were prepared and subjected to immunoblotting. Bands were visualized by probing with antibodies against Myc tag, Flag tag or actin. (C) HeLa cells were transiently transfected with SCAT1 and p210-Flag or a Flag-tagged kinase-dead mutant of p210BCR-ABL (p210KD-Flag) or pFlag empty vector. At $24 \mathrm{~h}$ after transfection, imatinib $(10 \mu \mathrm{M})$ was added and further cultured for $19 \mathrm{~h}$, cells were washed with PBS and then treated with serum-free DMEM with or without imatinib $(10 \mu \mathrm{M})$ for $5 \mathrm{~h}$. WCL were prepared and subjected to immunoblotting. Bands were visualized by probing with antibodies against Myc tag, Flag tag, phospho Tyr (p-Tyr) or actin. (D) K562 cells were transiently transfected with SCAT1 cDNA. At $43 \mathrm{~h}$ after transfection, cells were washed with PBS and then subjected to medium change to serum-free RPMI1640 for $5 \mathrm{~h}$. WCL and conditioned medium were prepared and subjected to immunoblotting. Bands were visualized by probing with antibodies against Myc tag or actin. 
colorimetric cell proliferation WST-8 [2-(2-methoxy-4nitrophenyl)-3-(4-nitrophenyl)-5-(2,4-disulfophenyl)-2Htetrazolium, monosodium salt] assay in 32D/TetOff-p210 cells. Cell viability decreased markedly in Tet-depleted 32D/TetOff-p210 cells compared with that in Tet-supplied 32D/TetOff-p210 cells and was partially, but significantly, restored by treatment with imatinib (Figure 2B, left). Tet and/or imatinib did not remotely affect cell viability in the parental 32D cells (Figure 2B, right). These results suggest that Tet-regulatable overexpression of p210BCR-ABL may decrease cell viability in a BCR-ABL tyrosine kinase activity-dependent manner in 32D/TetOff-p210 cells. p210BCR-ABL-induced decrease in cell viability observed in 32D/TetOff-p210 cells was unexpected because previous studies have shown that $\mathrm{p} 210 \mathrm{BCR}-\mathrm{ABL}$ activates phosphatidylinositol 3 kinase (PI3K)-Akt pathway to

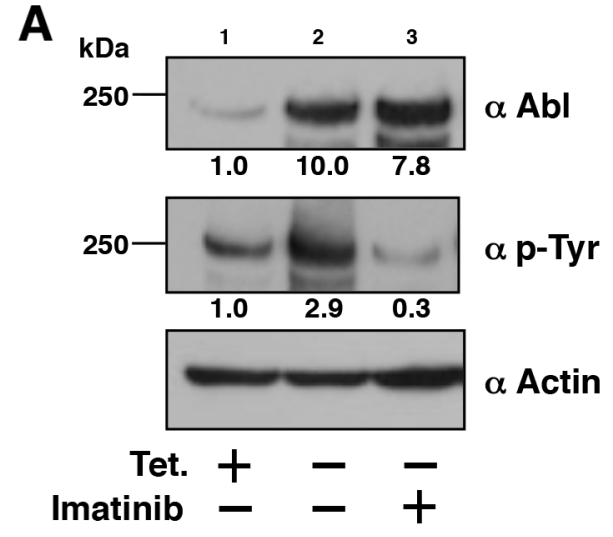

B

32D/TetOff-p210
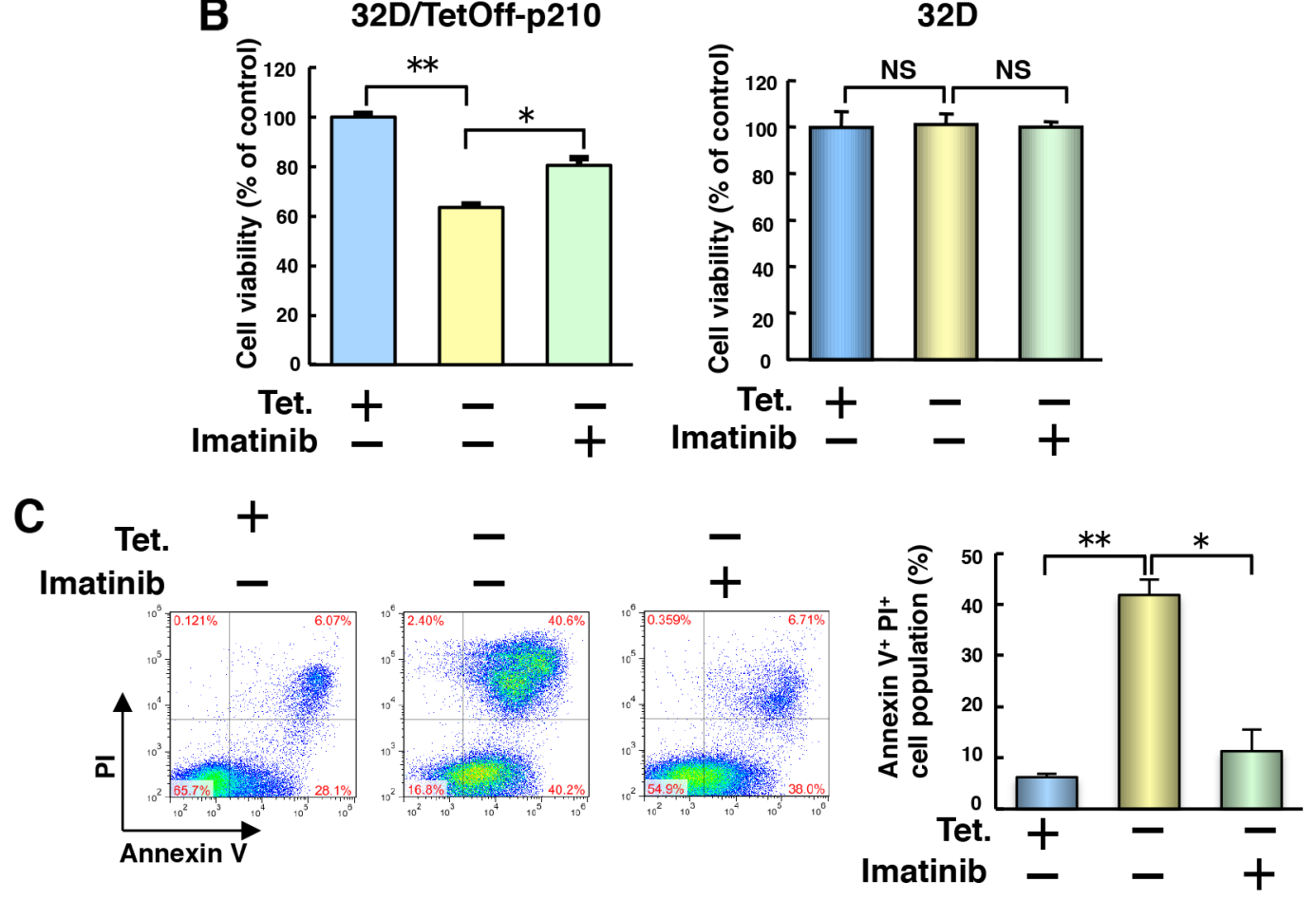

Figure 2: Tet-regulatable overexpression of p210BCR-ABL induces cell death in 32D/TetOff-p210 cells. (A) $32 \mathrm{D} /$ TetOff-p210 cells were Tet-supplied or depleted and then cultured for $48 \mathrm{~h}$ in the presence or absence of imatinib (1 $\mu \mathrm{M})$. WCL were subjected to immunoblotting. The values of relative band intensity versus the Tet $(+)$ control were shown below each panel. Data are representative of three independent experiments. (B) 32D/TetOff-p210 cells or parental 32D cells were Tet-supplied or depleted and then cultured with IL-3 supplement for $48 \mathrm{~h}$ in the presence or absence of imatinib $(1 \mu \mathrm{M})$. Cell viability was determined by WST-8 assay. ${ }^{*} P$ $<0.01,{ }^{* *} P<0.001$. Data are shown as mean $\pm \operatorname{SEM}(n=6)$ and are representative of three independent experiments. NS indicates no significant difference. (C) 32D/TetOff-p210 cells were Tet-supplied or depleted and then cultured for $96 \mathrm{~h}$ in the presence or absence of imatinib $(1 \mu \mathrm{M})$. Cells were double-stained with annexin V and PI and analyzed by flow cytometry. The proportion of cell population with the representative data is shown in each panel. Four independent double-staining experiments were performed and statistical analysis was executed. ${ }^{*} P<0.01,{ }^{* *} P<0.001$. Data are shown as mean $\pm \operatorname{SEM}(n=4)$. 
enhance cell growth [18] and Bcl-X transcription, through signal transducer and activator of transcription 5 (STAT5), to inhibit apoptosis in CML cells [19].

To examine the cause of decreased cell viability in 32D/TetOff-p210 cells, we next analyzed the mode of cell death by double staining using annexin $\mathrm{V}$ and propidium iodide (PI). p210BCR-ABL expression by Tetdepletion significantly increased the annexin $\mathrm{V}^{+} / \mathrm{PI}^{+}$cell population by $40.6 \%$ compared with that in Tet-supplied $(6.07 \%) 32 \mathrm{D} /$ TetOff-p210 cells and it was significantly restored by $6.71 \%$ in the presence of imatinib (Figure 2C). Furthermore, neither a necrosis inhibitor (IM-54) nor an apoptosis inhibitor (Q-VD-OPH) prevented p210BCRABL-induced cell death in Tet-depleted 32D/TetOff-p210 cells (Supplementary Figure 2). These results suggest that p210BCR-ABL-induced cell death is neither apoptosis [20] nor necrosis [21].

Tet-regulatable overexpression of p210BCR-ABL activates both caspase- 1 and caspase- 3 in $32 \mathrm{D} /$ TetOff-p210 cells

We then examined caspases as effectors of cell death in 32D/TetOff-p210 cells. Tet-regulatable overexpression of p210BCR-ABL by Tet-depletion induced expression of caspase-1 p10, cleaved caspase-3, and cleaved poly ADP ribose polymerase (PARP) (Figure 3A, lane 2), which was attenuated by the presence of imatinib in 32D/TetOff-p210 cells (Figure 3A, lane 3). FLICA (fluorescently labeled inhibitor of caspases), which is a non-cytotoxic and cellpermeable reagent for detection of activated caspases [22], showed that Tet-regulatable overexpression of p210BCRABL significantly activated caspase- 1 and caspase- 3 . Moreover, activated caspase- 1 and caspase- 3 were partially but significantly attenuated by the presence of imatinib in 32D/TetOff-p210 cells (Figure 3B). These results suggest that Tet-regulatable overexpression of p210BCR-ABL confers the combined feature of both activated caspase1 -induced pyroptosis and activated capase-3-induced apoptosis on 32D/TetOff-p210 cells. Furthermore, we tested whether glibenclamide, a NLRP3 inflammasome inhibitor, can prevent the activation of both caspase-1 and caspase- 3 induced by Tet-regulatable p210BCR-ABL expression in 32D/TetOff-p210 cells. Glibenclamide did not prevent the activation of both caspase-1 and caspase-3 (Supplementary Figure 3). These results suggest that NLRP3 may not be involved in the activation of both caspase- 1 and caspase-3 in 32D/TetOff-p210 cells.

\section{Induced production of proinflammatory cytokines by Tet-regulatable overexpression of p210BCR- $A B L$ in 32D/TetOff-p210 cells and enhanced production of S100A8/A9 in BCR-ABL TG mice}

Caspase- 1 activation leads to the secretion of proinflammatory cytokines [6], and CML stem cells produce a higher level of TNF- $\alpha$ than that by normal counterparts, as described previously [23]. Therefore, we measured the concentration of IL- $1 \beta$ and TNF- $\alpha$ in the culture supernatant of 32D/TetOff-p210 cells. Tet-regulatable overexpression of p210BCR-ABL by Tet-depletion significantly induced the secretion of IL-1 $\beta$ and TNF- $\alpha$ into the culture supernatant, which was almost completely inhibited by the treatment with imatinib in 32D/TetOff-p210 cells (Figure 4A). However, the secretion of these cytokines was not observed in parental 32D cells (Figure 4A). These results suggest that $\mathrm{p} 210 \mathrm{BCR}-\mathrm{ABL}$-induced cell death is similar to pyroptosis [24]. To investigate the biological function of TNF- $\alpha$ and IL- $1 \beta$ in inducing cell death, we tested the effect of blocking antibodies against cell death of 32D/TetOff-p210 cells. Neither blocking antibody against TNF- $\alpha$ nor IL- $1 \beta$ prevented p210BCR-ABL-induced cell death in 32D/TetOff-p210 cells (Supplementary Figure 4). These data suggests that $\mathrm{p} 210 \mathrm{BCR}-\mathrm{ABL}$-induced cell death is independent of both activities of TNF- $\alpha$ and IL- $1 \beta$.

S100A8 and S100A9 are induced by primary tumor and chemoattract $\mathrm{CD} 11 \mathrm{~b}^{+}$bone marrow-derived cells in pre-metastatic lungs, as reported previously by us [25]. A recent study has shown that S100A8 and S100A9 induce the secretion of cytokines, such as IL$1 \beta$, IL-6, IL-8, and increase the inflammasome NLRP3 via reactive oxygen species (ROS)-dependent activation of nuclear factor- $\kappa \mathrm{B}(\mathrm{NF}-\kappa \mathrm{B})$ in human peripheral blood mononuclear cells [26]. Interestingly, Tet-regulatable overexpression of $\mathrm{p} 210 \mathrm{BCR}-\mathrm{ABL}$ by Tet-depletion significantly induced the secretion of S100A8/A9 heterodimer into the cell culture supernatant, which was also completely inhibited by treatment with imatinib in 32D/TetOff-p210 cells (Figure 4B, left). Furthermore, Tet-regulatable overexpression of p210BCR-ABL by Tet-depletion also induced $\mathrm{S} 100 \mathrm{~A} 8$ proteins by 13.3-fold and S100A9 by 1.8 -fold in WCL of 32D/ TetOff-p210 cells (Figure 4B, right, lanes 1 vs 2). Imatinib inhibited the upregulation of S100A8 but not S100A9 in WCL of 32D/TetOff-p210 cells (Figure 4B, right, lane 3). These results suggest that S100A8, but not S100A9, was primarily induced by Tetregulatable overexpression of $\mathrm{p} 210 \mathrm{BCR}-\mathrm{ABL}$ in $32 \mathrm{D} /$ TetOff-p210 cells and may participate in the regulation of inflammasome. To examine the level of S100A8/A9 production in CML in vivo, we analyzed BCR-ABL TG mice [27] as a human CML model. In ELISA assay, plasma S100A8/A9 level was significantly induced in BCR-ABL TG mice compared with that in wildtype (WT) mice (Figure 4C). Furthermore, mRNA expressions of both S100a8 and S100a9 in the spleen were significantly enhanced in BCR-ABL TG mice compared with those in WT mice (Figure 4D). These results suggest that S100A8/A9 may participate in the progression of CML in vivo. 
Tet-regulatable overexpression of p210BCR-ABL induces differentiation from myeloid progenitor cells into G-MDSC in 32D/TetOff-p210 cells

Although roughly $40 \%$ of the $32 \mathrm{D} /$ TetOff-p 210 cells showed cell death $96 \mathrm{~h}$ after Tet-deprivation (Figure $2 \mathrm{C}$ ), it is not clear that whether differentiation occurred before cell death. Because 32D cells can differentiate into neutrophils in response to G-CSF stimulation [17] and S100A8 proteins are abundantly expressed in neutrophils [28], we next performed Giemsa staining to examine whether Tet-regulatable overexpression of p210BCR-ABL induced segmentation of nuclei. Tet-regulatable overexpression of p210BCR-ABL by Tet-depletion partially induced the differentiation from myeloid progenitors into neutrophil-like cells, characterized by segmented nuclei (indicated by arrows) in $32 \mathrm{D} /$ TetOff-p210 cells, and was almost completely inhibited by treatment with imatinib (Figure 5A). Furthermore, the $\mathrm{CD} 11 \mathrm{~b}^{+} \mathrm{Ly} 6 \mathrm{C}^{+} \mathrm{Ly} 6 \mathrm{G}^{+}$cell population was specifically increased by $24.8 \%$ in Tet-depleted $32 \mathrm{D} /$ TetOff-p210 cells compared with that in Tet-supplied one (3.7\%), and the increase in the $\mathrm{CD} 11 \mathrm{~b}^{+} \mathrm{Ly} 6 \mathrm{C}^{+} \mathrm{Ly} 6 \mathrm{G}^{+}$ cell population in Tet-depleted 32D/TetOff-p210 cells was significantly inhibited by the presence of imatinib (reduced to $1.26 \%$ ) (Figure 5B and 5C). Meanwhile, the CD $11 b^{+}{ }^{+}$y $6 \mathrm{C}^{+} \mathrm{Ly}_{6 \mathrm{G}}{ }^{+}$cell population was only $0.011 \%$ in parental 32D cells (Supplementary Figure 5). We
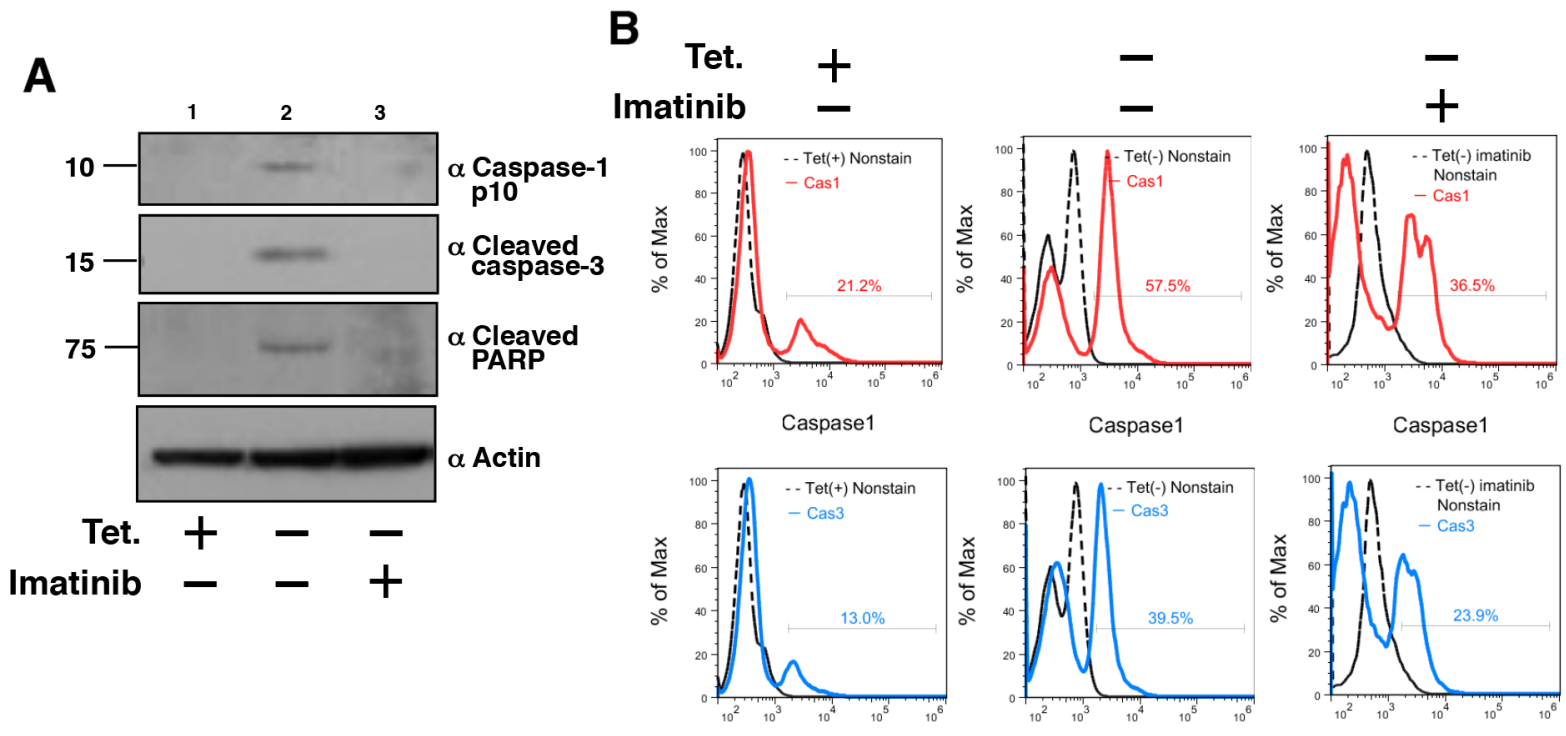

Caspase 3

Caspase 3

Caspase 3
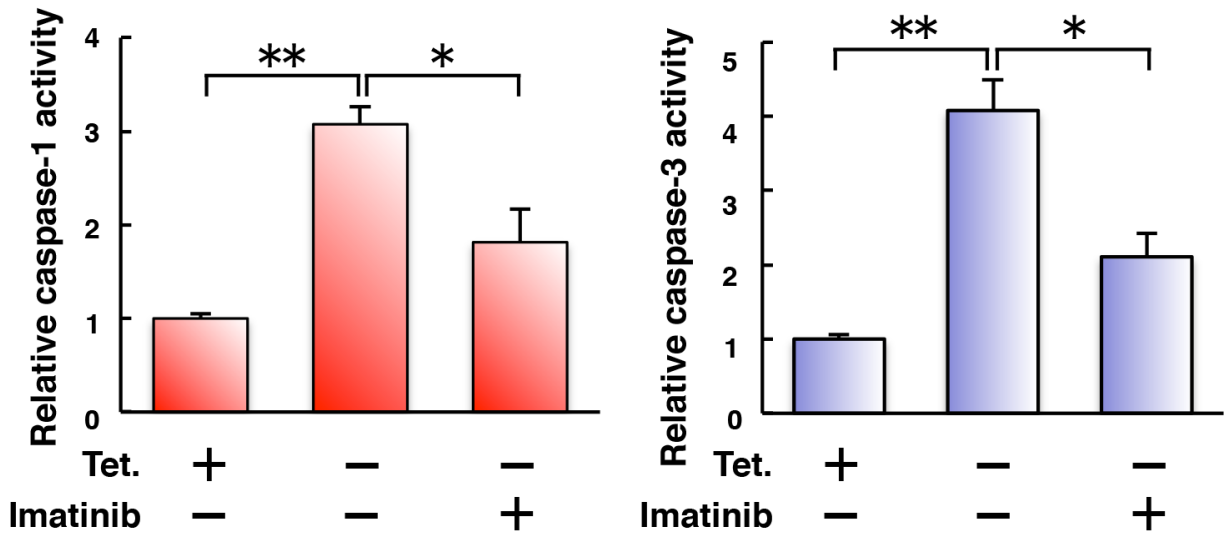

Figure 3: Tet-regulatable overexpression of p210BCR-ABL activates both caspase-1 and caspase-3 in 32D/TetOff-p210 cells. (A) 32D/TetOff-p210 cells were Tet-depleted and then cultured for $48 \mathrm{~h}$. WCL were subjected to immunoblotting. Bands were visualized by probing with antibodies against caspase-1 p10, cleaved caspase-3 or cleaved PARP. (B) 32D/TetOff-p210 cells were Tetdepleted or supplied and then cultured in the presence or absence of imatinib $(1 \mu \mathrm{M})$ for $96 \mathrm{~h}$ and then incubated with FLICA 660 active caspase-1 or caspase-3 detection probe and analyzed by flow cytometry. The merged histogram (solid line) with non-stain control (dashed line) is shown in each panel. The proportion of FLICA-positive cell population max is shown in each panel. Three independent FLICA caspase- $1 / 3$ assays were performed, and statistical analysis was executed, as shown in lower graphs. ${ }^{*} P<0.05,{ }^{* *} P<0.01$. Data are shown as mean $\pm \operatorname{SEM}(n=3)$. 
examined p210BCR-ABL-induced both cell death and differentiation at both $48 \mathrm{~h}$ and $96 \mathrm{~h}$ after Tet-depletion in 32D/TetOff-p210 cells. The CD11b+Ly6C ${ }^{+} \mathrm{Ly}_{6 \mathrm{G}}{ }^{+}$ cell population was only $0.13 \%$ at $48 \mathrm{~h}$ and it was increased by $7.84 \%$ at $96 \mathrm{~h}$ (Supplementary Figure 6A). Meanwhile, the $\mathrm{PI}^{+}$cell population was $38.6 \%$ at $48 \mathrm{~h}$ and it was increased by $58.8 \%$ at $96 \mathrm{~h}$ (Supplementary Figure 6B). We showed the 100\% stacked column chart dividing whole cell population into living cells

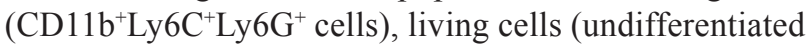
cells), and dead cells ( $\mathrm{PI}^{+}$cells) in Tet-depleted 32D/ TetOff-p210 cells (Supplementary Figure 6C). These
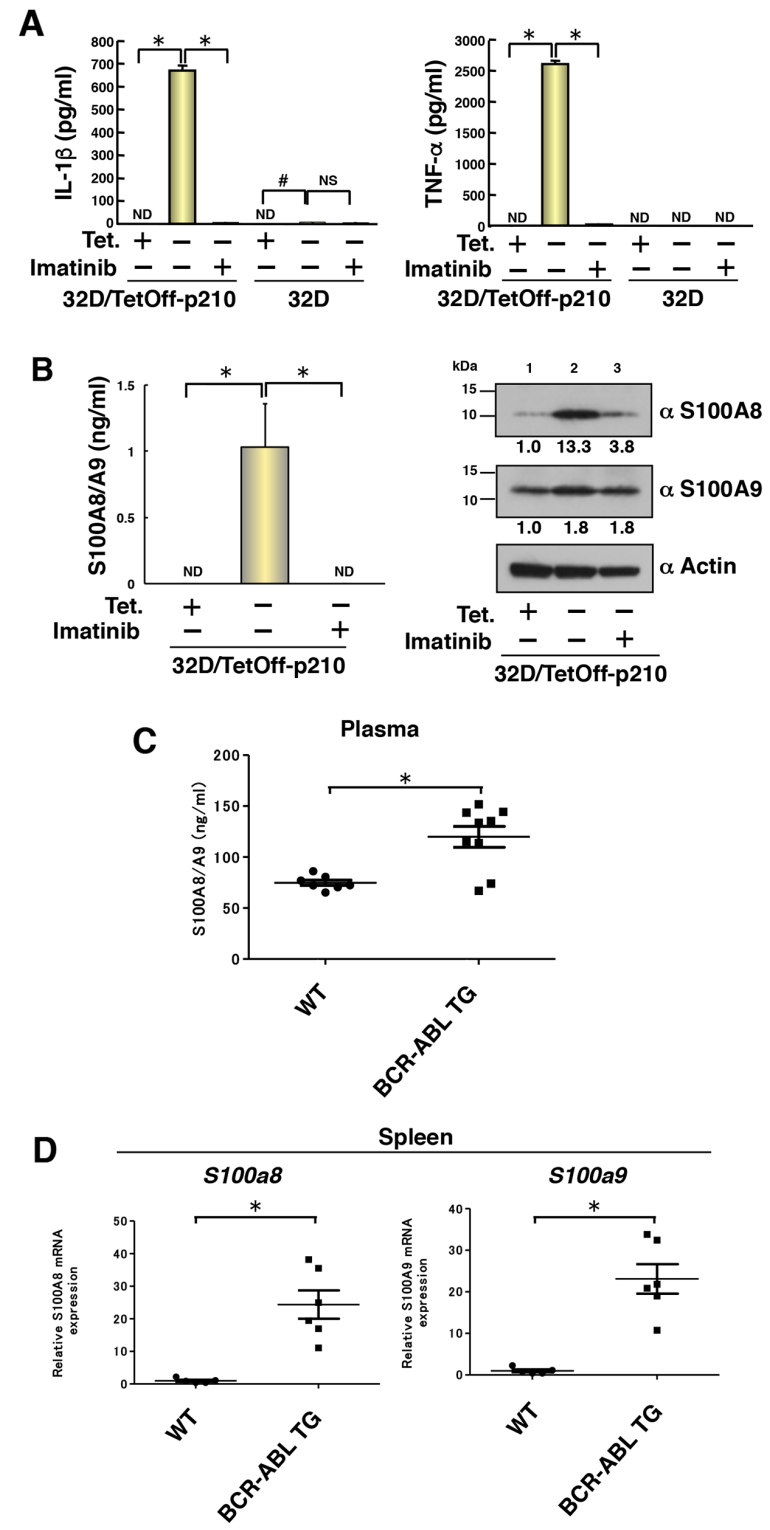

Figure 4: Induced production of proinflammatory cytokines by Tet-regulatable overexpression of p210BCR-ABL in 32D/TetOff-p210 cells and enhanced production of S100A8/A9 in BCR-ABL TG mice. 32D/TetOff-p210 cells or parental 32D cells were Tet-supplied or depleted and then cultured with IL-3 supplement for $96 \mathrm{~h}$ to collect the culture supernatant and WCL. (A) ELISA was performed to determine concentration of IL- $1 \beta$ and TNF- $\alpha$ in the culture supernatant. ${ }^{*} P<0.001$, ${ }^{\#} P<0.05$. Data are shown as mean $\pm \operatorname{SEM}(n=3)$ and are representative of three independent experiments. ND indicates not detected (under the detection limit). NS indicates no significant difference. (B) ELISA was performed to determine concentration of S100A8/A9 in the culture supernatant. ${ }^{*} P<$ 0.05. Data are shown as mean $\pm \operatorname{SEM}(n=3)$. ND indicates not detected (under the detection limit). WCL were subjected to immunoblotting. Bands were visualized by probing with antibodies against S100A8, S100A9 or actin. The values of relative band intensity versus the Tet $(+)$ control are shown under each panel. (C) ELISA was performed to determine concentration of S100A8/A9 in the plasma of 8-month-old WT $(n=7)$ and BCR-ABL TG $(n=9)$ mice. Data are shown as mean \pm SEM. ${ }^{*} P<0.05$. (D) Expressions of both $S 100 a 8$ and $S 100 a 9$ in the spleen of 8-month-old WT $(n=5)$ and BCR-ABL TG $(n=6)$ mice were determined by quantitative RT-PCR. Data are shown as mean \pm SEM. ${ }^{*} P<0.005$. Statistical significance was evaluated by Mann-Whitney $U$ test. 
data suggest that the cells survived from p210BCRABL expression differentiate into G-MDSC. Although differentiated cells eventually die, we cannot perfectly show evidence that G-MDSC differentiation is prerequite for cell death. Furthermore, mRNA expression of CCAAT/enhancer binding protein $\alpha(\mathrm{C} / \mathrm{EBP} \alpha)$, the principal regulator of granulocytic differentiation, was detected in both Tet-supplied or Tet-depleted 32D/ TetOff-p210 cells, and Cebpa mRNA expression in Tetdepleted cells was significantly inhibited in the presence of imatinib (Supplementary Figure 7, left). Our data suggest that Tet-regulatable overexpression of $\mathrm{p} 210 \mathrm{BCR}$ ABL induces differentiation from myeloid progenitor cells into G-MDSC in 32D/TetOff-p210 cells.

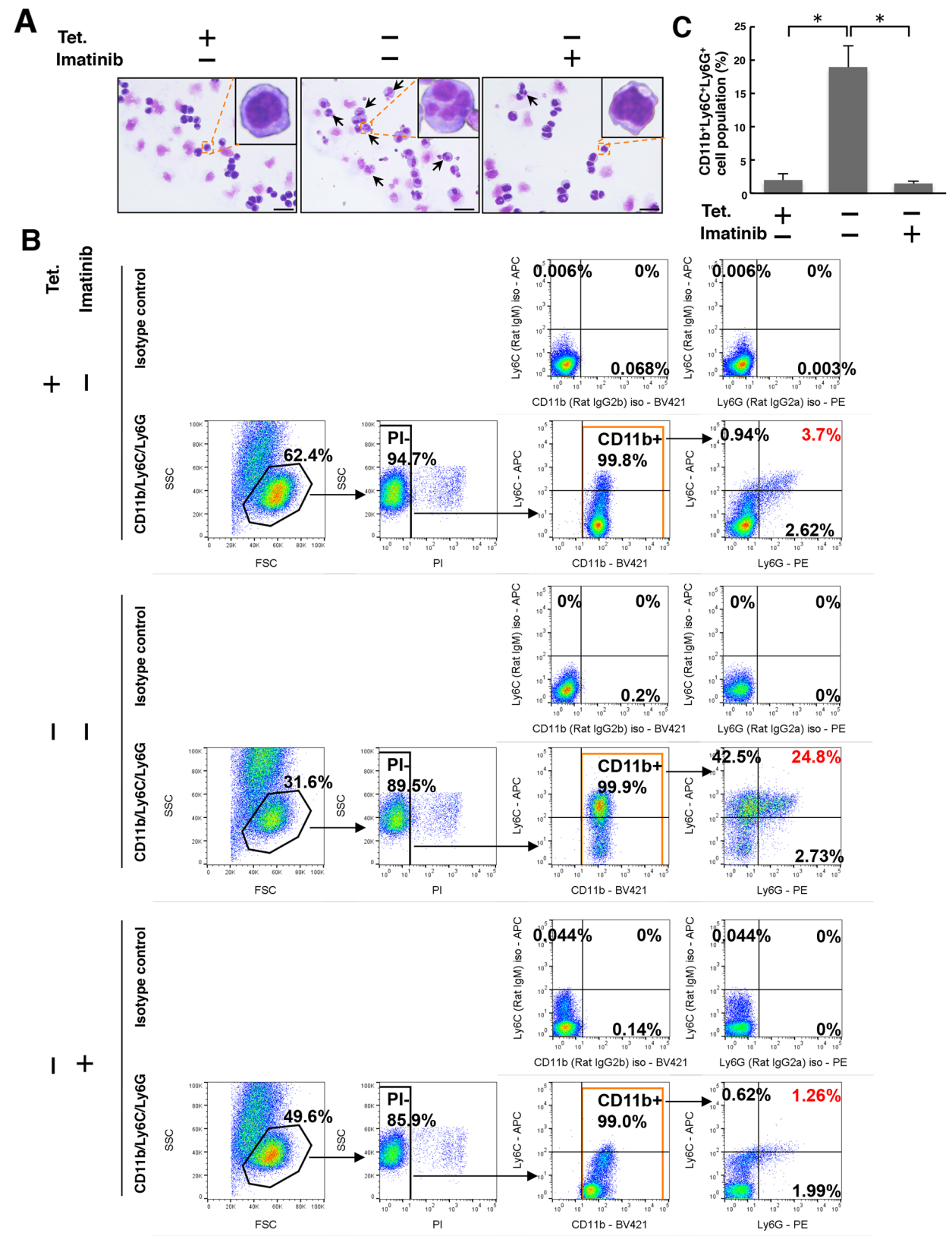

Figure 5: Tet-regulatable overexpression of p210BCR-ABL induces differentiation from myeloid progenitors into G-MDSC in 32D/TetOff-p210 cells. 32D/TetOff-p210 cells were Tet-supplied or depleted and then cultured in the presence or absence of imatinib $(1 \mu \mathrm{M})$ for $96 \mathrm{~h}$. (A) Giemsa staining was performed. Cells with segmented nuclei (indicated by arrows) are shown in each panel. Scale bar, $10 \mu \mathrm{m}$. (B) Cells were triple-stained with anti-CD11b-BV421, anti-Ly6C-APC, and anti-Ly6G-PE, or isotype anti-rat IgG2b-BV421, anti-rat IgM-APC, and anti-rat IgG2a-PE. Stained cells were analyzed by flow cytometry. The obtained data were processed by selection of PI- and $\mathrm{CD}^{-} 1 \mathrm{~b}^{+}$cell population, and then the cell surface expression of Ly6C and Ly6G within the CD11 ${ }^{+}$cell population was analyzed. Numbers in the plots indicate the percentages of gated cells. (C) Three independent triple-staining experiments, as exemplified in panel $\mathrm{B}$, were performed, and statistical analysis was executed. ${ }^{*} P<0.01$. Data are shown as mean $\pm \operatorname{SEM}(n=3)$. 


\section{In vivo analysis of differentiation into G-MDSC in a CML murine model}

To examine G-MDSC differentiation in vivo in a CML murine model, we collected cells from the spleen of BCR-ABL TG and WT mice. Both spleen and relative spleen weight increased in 8-month-old male BCR-ABL TG mice compared with those in WT mice (Figure 6A and 6B). According to flow cytometric analysis, G-MDSC population $\left(\mathrm{CD} 11 \mathrm{~b}^{+} \mathrm{Ly} 6 \mathrm{C}^{+} \mathrm{Ly}_{6} \mathrm{G}^{+}\right)$ significantly increased in the spleen of BCR-ABL TG mice compared with that in WT mice (Figure 6C and 6D). Individual data of flow cytometric analysis (BCR-ABL TG; $n=6$, WT; $n=4$ ) are also shown in Supplementary Figure 8. These data suggest that increased numbers of splenic G-MDSC may contribute to immunosuppression following the development of CML in the TG model.

\section{DISCUSSION}

In the present study, we clearly revealed that the Tet-regulatable overexpression of p210BCR-ABL induces granulocytic differentiation from myeloid progenitor cells in the 32D/TetOff-p210 cells. Previous studies have shown that G-CSF receptor mRNA is suppressed in v-abl-transformed 32Dcl3 [29], and two CML cell lines, K562 and BV173, do not express G-CSF mRNA [30]. Our findings are not consistent with a previous report in which granulocytic differentiation was inhibited in 32Dcl3 cells stably expressing p210BCR-ABL (32D/p210BCR$\mathrm{ABL}$ cells) caused by transcriptional suppression of G-CSF receptor, possibly through downregulation of $\mathrm{C} /$ EBP $\alpha[31,32]$. These studies, which are totally different from our experimental system, were performed using 32D/p210BCR-ABL cells, which are insusceptible to G-CSF because of G-CSF receptor is not detected even in the presence of G-CSF. However, our established 32D/ TetOff-p210BCR-ABL cells exhibited susceptibility to G-CSF because expressions of both G-CSF receptor $(C s f 3 r)$ and G-CSF (Csf3) were significantly induced by Tet-regulatable overexpression of p210BCR-ABL, which was restored by treatment with imatinib (Supplementary Figure 7, left). In neutrophils of patients with CML, p210BCR-ABL levels decrease compared with those in immature CML cells but are still retained [33]. G-CSF receptor expression in neutrophils of patients with CML is also observed [34]. Therefore, we assume that G-CSF

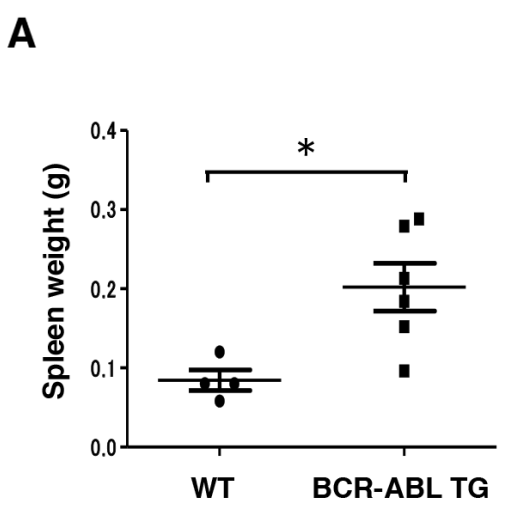

C

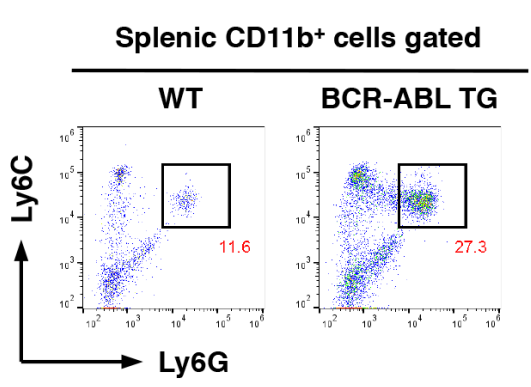

B

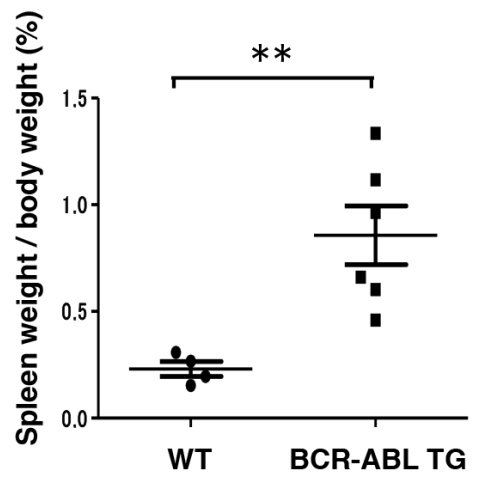

D

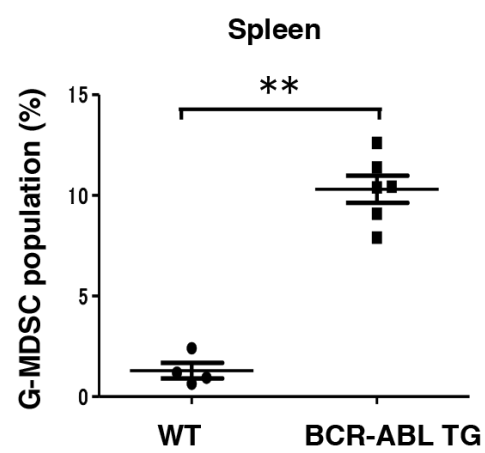

Figure 6: Differentiation into G-MDSC was enhanced in the spleen of BCR-ABL TG mice. (A and B) Absolute spleen weight and relative spleen weight to the whole-body weight of 8-month-old male WT $(n=4)$ and BCR-ABL TG $(n=6)$ mice. Data are shown as mean \pm SEM. ${ }^{*} P<0.05,{ }^{* *} P<0.01$. (C) Representative plots of G-MDSCs (Ly6C ${ }^{+}$and Ly6G $\mathrm{G}^{+}$cells after gating on CD11b cells) in the spleen of 8-month-old male WT and BCR-ABL TG mice. Numbers in the plots indicate the percentages of gated cells. (D) Relativeratios of G-MDSCs in the spleen of 8-month-old male WT $(n=4)$ and BCR-ABL TG $(n=6)$ mice. Data are shown as mean $\pm \operatorname{SEM}$. ${ }^{* *} P<0.01$. 
signaling via G-CSF receptor may involve granulocytic differentiation in patients with CML.

Although the reported HL-60/Bcr-Abl and K562 cells are in a chronic state, imatinib failed to decrease both differentiation and apoptosis in those cells [35], this phenomenon may be experimentally restricted to 32D/TetOff-p210 cells. Although we showed that K562 cells had a SCAT1 cleavage activity (Figure 1D), a high rate of spontaneous cell death was not observed in K562 cells as compared with Tet-depleted 32D/TetOff-p210 cells (Supplementary Figure 9). Therefore, p210BCRABL-induced both cell death and differentiation may be experimentally restricted to 32D/TetOff-p210 cells.

Our findings suggest that Tet-regulatable overexpression of p210BCR-ABL-induced cell death and differentiation may be relevant to the induction of G-MDSC in CML. A recent study has shown that the frequency of G-MDSC is significantly increased in patients with CML compared with that in healthy donors and that CML patient-derived mesenchymal stem cells activate G-MDSC, which express higher levels of arginase- 1 , TNF- $\alpha$, and IL-1 $\beta$ mRNA [36]. Several clinical studies have shown that imatinib reduces G-MDSC numbers, which exert immunosuppressive activity linked to arginase-1-induced inhibitory effect on $\mathrm{T}$ cells, in patients diagnosed with $\mathrm{CML}[37,38]$. These reports are partially consistent with our findings. Imatinib reduces the number of progenitor cells from which G-MDSC differentiate, therefore imatinib can probably decrease G-MDSC numbers. We showed that G-MDSC differentiation per se is dependent on the tyrosine kinase activity of p210BCR-ABL in an imatinibsensitive manner. The differentiation is accompanied by $\mathrm{C} / \mathrm{EBP} \alpha$ upregulation, which is consistent with a previous report [39]. An interesting finding is the upregulation of S100A8/A9 that is responsible for activation of MDSC [40], which was also demonstrated in our CML mice model (Figure 4C and 4D). Although we have not tested if sorted G-MDSC from BCR-ABL TG mice are susceptible to cytotoxic drugs including imatinib, those cells express both TLR4 and S100A8 [25] can activate $\mathrm{NF}-\kappa \mathrm{B}$ [41] in those cells possibly giving resistance against cell death.

Because a previous study has shown that the nuclear entrapment of p210BCR-ABL induces apoptosis of CML cells [42], we hypothesized that p210BCR-ABLinduced cell death observed in 32D/TetOff-p210 cells may be caused by the nuclear entrapment of p210BCRABL. To test this hypothesis, we examined the cellular localization of p210BCR-ABL in 32D/TetOff-p210 cells. Immunofluorescent staining using anti-Abl antibody showed that Tet-depletion-induced p210BCR-ABL proteins were predominantly localized in the cytosol but not in the nucleus (Supplementary Figure 10). Imatinib did not affect the localization of p210BCR-ABL (Supplementary Figure 10). These results suggest that
p210BCR-ABL-induced cell death is not caused by the nuclear entrapment of p210BCR-ABL in 32D/TetOff-p210 cells.

Imatinib is an effective drug for targeting chronic phase CML. However, imatinib resistance is a problem, particularly in the advanced CML phase. Resistance mechanisms are currently explained by additional genetic mutation, natural imatinib resistance in CML stem cells, and overexpression of BCR-ABL $[2,16,43]$. Our results may provide insights into the overexpressionrelated resistance. Our data suggest that a paradoxical counteraction of imatinib against cell survival exists in CML. However, it may be possible that imatinib exerts different effects between proliferating cells and differentiating cells in CML, meaning that imatinib exerts growth-inhibitory effects against proliferating cells, as exemplified in 32D/p210BCR-ABL cells, and differentiation-suppressive effects against differentiating cells, as exemplified in Tet-regulatable p210BCR-ABLexpressing 32D/TetOff-p210 cells. A clinical report has suggested synergistic effects of imatinib and G-CSF against CML [44].

In the present study, we propose a novel mode of cell death, proposed as myeloptosis, which has combined features of caspase-1-induced pyroptosis and caspase-3induced apoptosis, coincident with the differentiation from myeloid progenitors into G-MDSC and the secretion of IL-1 $\beta$, TNF- $\alpha$, and S100A8/A9 induced by Tet-regulatable overexpression of p210BCR-ABL in 32D/TetOff-p210 cells. Furthermore, increased numbers of G-MDSC due to enhancement of $\mathrm{S} 100 \mathrm{~A} 8 / \mathrm{A} 9$ production were observed in TG mice expressing p210BCR-ABL. Myeloptosis may create a vicious cycle comprising a continuous loop of cell death-induced secretion of proinflammatory cytokines and accumulation of G-MDSC in CML possibly responsible for immunosuppression.

\section{MATERIALS AND METHODS}

\section{Materials}

Antibody against Flag tag and CHX were purchased from Sigma-Aldrich (St Louis, MO, USA). Antibody against Myc tag was purchased from Life technologies (Rockville, MD, USA). Antibody against actin and IM-54 was purchased from Merck Millipore (Billerica, MA, USA). Antibodies against Abl (sc-23), phospho Tyr (PY99, sc-7020), caspase-1 p10 (sc-514), S100A8 (sc-8113), S100A9 (sc-8115) and caspase-1 inhibitor (z-YVAD-fmk) were purchased from Santa Cruz Biotechnology (Santa Cruz, CA, USA). Antibodies against cleaved caspase-3 and cleaved PARP were purchased from Cell Signaling Technology (Danvers, MA, USA). Blocking antibody against mouse TNF and purified $\mathrm{NA} / \mathrm{LE}$ hamster IgG1, $\lambda 1$ isotype control was purchased from BD Biosciences (San Jose, CA, USA). Blocking antibody against mouse IL-1 $\beta$ was purchased from R\&D systems. 
(Minneapolis, MN, USA). Imatinib mesylate was purchased from Novartis (Basel, Switzerland). Human TNF- $\alpha$ was purchased from Peprotech (Rocky Hill, NJ, USA). Q-VDOPH was purchased from TONBO biosciences (San Diego, CA, USA). Glibenclamide was purchased from Wako (Osaka, Japan).

\section{Plasmids}

SCAT1 cDNA, which was subcloned in-frame into pcDNA3.1 vector (Life technologies), was kindly donated from Dr. Yoshifumi Yamaguchi and Dr. Masayuki Miura. p210BCR-ABL and p210BCR-ABL kinase dead (KD, ABL K290R) mutant cDNA were subcloned in-frame into pFlagCMV2 vector (Sigma-Aldrich). Tet-regulatable p210BCRABL construct, pUHD 10-3 BCR-ABL IRES GFP, and Tet-regulated transactivator (tTA) expression vector, pCAG20-1, were kindly donated from Dr. Owen N. Witte.

\section{Animal experiments}

$\mathrm{p} 210^{\text {brrabl }}$ TG (BCR-ABL ${ }^{\text {tg/- }}$; BCR-ABL TG) mice were generated as previously described [27]. The normal littermates of these mice $\left(b c r /-a b l^{-}\right)$were used as controls. Mice at 8 months of age that already exhibited a CML-like phenotype were sacrificed, and spleen cells were collected by a standard procedure. Experimental procedures performed on mice were approved by the Animal Research Committee of Tokyo Women's Medical University (AE17-59).

\section{Cell culture}

The human cervical carcinoma cell line HeLa was cultured in DMEM with $10 \%(\mathrm{v} / \mathrm{v}) \mathrm{FBS}$ at $37^{\circ} \mathrm{C}$ under $5 \%$ $\mathrm{CO}_{2}$ in air. The human CML cell line $\mathrm{K} 562$ was cultured in RPMI1640 with $10 \%(\mathrm{v} / \mathrm{v})$ FBS at $37^{\circ} \mathrm{C}$ under $5 \%$ $\mathrm{CO}_{2}$ in air. Mouse myeloid progenitor 32D cells were pharchased from RIKEN BioResouce Centaer Cell Bank (RBRC-RCB1145; Tsukuba, Ibaraki, Japan) and cultured in RPMI1640 supplemented with 10\%(v/v) FBS and 10\%(v/v) IL-3 culture supplement (Corning, NY, USA), defined as the $32 \mathrm{D}$ growth media, at $37^{\circ} \mathrm{C}$ under $5 \% \mathrm{CO} 2$ in air. $32 \mathrm{D} /$ TetOff-p210 cells were maintained in 32D growth media supplemented with Tet $(1 \mu \mathrm{g} / \mathrm{ml})$ without IL-3 culture supplement. For Tet-depletion, cultured cells were washed two times with RPMI1640 supplemented with 10\%(v/v) FBS and were then cultured in $32 \mathrm{D}$ growth media without Tet. $\mathrm{Ba} / \mathrm{F} 3$ cells stably expressing Flag-tagged p210BCRABL were cultured in RPMI1640 supplemented with $10 \%(\mathrm{v} / \mathrm{v}) \mathrm{FBS}$. All cell lines using in the present study were mycoplasma-negative certificated by using MycoAlert ${ }^{\mathrm{TM}}$ Mycoplasma Detection Kit (Lonza, Allendale, NJ, USA).

\section{Transfection}

Transfection was performed by electroporation using an Amaxa CLB transfection reagent (Lonza), according to the manufacturer's protocol.

\section{Immunoblotting}

WCL were prepared by cell lysis with $50 \mathrm{mM}$ Tris- $\mathrm{HCl}$ ( $\mathrm{pH} 7.4) / 0.1 \% \mathrm{SDS} / 0.5 \% \mathrm{NP}-40$, containing protease inhibitor mixtures, on ice for $30 \mathrm{~min}$. Next, the supernatant was collected after centrifugation (15,000 rpm for 10 minutes). The conditioned medium was prepared by collecting the supernatant after centrifugation (1,500 rpm for 5 minutes) and condensed by trichloroacetic acid precipitation. The samples were mixed with a SDS sample buffer containing 2-mercaptoethanol and boiled for $3 \mathrm{~min}$, electrophoresed on precast gradient gels (Wako, SuperSep ${ }^{\mathrm{TM}}$ Ace, 5-20\% or $10-20 \%$ ), and electro-transferred using a Trans-BlotTurbo transfer system (Bio-rad, Hercules, CA, USA) to a polyvinylidene difluoride membrane (Bio-Rad). The membranes were blocked with TBS- $0.1 \%$ (v/v) Tween 20 (TBS-T) with $0.5 \%(\mathrm{w} / \mathrm{v})$ non-fat milk, and were incubated with a primary antibody overnight, followed by TBS-T washes and incubation with a horseradish peroxidaseconjugated secondary antibody for $30 \mathrm{~min}$. Protein bands were developed using Pierce Western Blotting Substrate (Thermo Fisher Scientific, Waltham, MA, USA).

\section{WST-8 assay}

Cell viability was determined by colorimetric cell proliferation assay using WST-8. WST-8 is a non-cell permeable compound, which is reduced by mitochondrion dehydrogenase to form the water-soluble formazan dye that is directly proportional to viable cells. 32D/TetOff-p210 or parental $32 \mathrm{D}$ cells $\left(1 \times 10^{4}\right.$ cells $)$ were Tet-supplied or depleted and then cultured with IL-3 supplement in the presence or absence of imatinib $(1 \mu \mathrm{M})$ for $48 \mathrm{~h}$ in a $96-$ well microplate. Cell counting kit- 8 reagent (DOJINDO LABORATORIES, Kumamoto, Japan) was added to each well and then incubated at $37^{\circ} \mathrm{C}$ for $4 \mathrm{~h}$. After incubation, absorbans at $450 \mathrm{~nm}$ was measured using Multiscan ${ }^{\mathrm{TM}} \mathrm{GO}$ Microplate Spectrophotometer (Thermo Fisher Scientific) to determine cell viability.

\section{Immunofluorescence microscopy}

Cultured cells were mounted with Smear Gell (GenoStaff, Tokyo, Japan) on APS-coated slide glass (Matsunami glass, Osaka, Japan) and fixed with 4\%(w/v) paraformaldehyde/phosphate buffered saline (PBS) (Wako) for 20 minutes. After fixing, cells were washed with PBS and incubated with $0.1 \%(\mathrm{v} / \mathrm{v})$ Triton X-100 for 5 min. After blocking in Blocking One Histo (Nakarai tesque, Kyoto, Japan) for $30 \mathrm{~min}$ at room temperature, a primary antibody against Abl was added to the cells. The cells were then washed three times with PBS and incubated with Alexa Fluor 555 labeled anti-mouse IgG antibody (Life technologies). The images were obtained using a confocal laser scanning microscope (LSM510 META, Carl Zeiss) and processed using Zeiss LSM Image Browser version 4.2. 


\section{Flow cytometry}

Double staining of annexin $\mathrm{V}$ and PI was performed using Annexin V Apoptosis detection set phycoerythrin (PE)-Cy7 (eBioscience, San Diego, CA, USA) or Brilliant Violet 421 ${ }^{\mathrm{TM}}$ (BV421) Annexin V (BioLegend, San Diego, CA, USA), and activated caspases detection was performed using a FLICA 660 caspase-1 or caspase-3/-7 assay kit (Immunochemistry Technologies, Bloomington, MN, USA) according to the manufacturer's protocol. Stained cells were analyzed with a flow cytometer Cytomics FC 500 (Beckman Coulter, Fullerton, CA, USA). Triple staining of CD11b, Ly6C, and Ly6G for 32D/TetOff-p210 cells was performed using anti-CD11b-BV421, anti-Ly6Callophycocyanin (APC) (BD Biosciences), and anti-Ly6GPE (BD Biosciences), respectively. Stained cells were analyzed with a high-speed cell sorter MoFlo Astrios ${ }^{\mathrm{EQ}}$ (Beckman Coulter, Fullerton, CA, USA). Triple staining of CD11b, Ly6C, and Ly6G for spleen cells from mice was performed using anti-CD11b-PE (BD Biosciences) antiLy6C-APC (BD Biosciences), and anti-Ly6G-fluorescein isothiocyanate (FITC) (BD Biosciences), respectively. Stained cells were analyzed with a flow cytometer Cytomics FC 500 (Beckman Coulter).

\section{Giemsa staining}

32D/TetOff-p210 cells were Tet-supplied or depleted and then cultured in the presence or absence of imatinib $(1 \mu \mathrm{M})$ for $96 \mathrm{~h}$. Next, a smear was prepared on a slide glass and fixed with $100 \%$ methanol for $2 \mathrm{~min}$. After fixing, Giemsa staining solution diluted using M/150 phosphate buffer (pH6.4) was added and incubated for $20 \mathrm{~min}$. After washing with distilled water, the prepared slide was allowed to air-dry and was visualized under the microscope.

\section{ELISA}

The concentration of mouse IL- $1 \beta$ and TNF- $\alpha$ in the cell culture supernatants was determined using the Quantikine ELISA Kit (R\&D systems) according to the manufacturer's protocol. The concentration of mouse S100A8/A9 complex in the cell culture supernatants was determined using S100A8/ A9 ELISA kit (Immundiagnostik AG, Bensheim, Germany) according to the manufacturer's protocol.

\section{Quantitative RT-PCR analysis}

Total RNA was isolated from cells using ISOGEN II (Nippon Gene, Tokyo, Japan). cDNA was synthesized using PrimeScript ${ }^{\mathrm{TM}}$ II with an Oligo $(\mathrm{dT})_{15}$ Primer (Takara Bio, Shiga, Japan). Quantitative PCR analysis was performed using the SYBR ${ }^{\circledR}$ Premix Ex Taq II (Takara Bio) and then quantified using StepOnePlus ${ }^{\mathrm{TM}}$ Real Time PCR system (Applied Biosystems, Foster City, CA, USA). For S100a8 and S100a9 analysis, RNA was reverse transcribed and quantitative PCR analysis was performed using SYBR Green master mixture (TOYOBO) and ABI 7500 Sequence Detection System (Applied Biosystems). Gene level was calculated from cycle threshold values, and a logarithm of the copy number of a target gene was confirmed to be on a linear line using the corresponding isolated DNA and its serial dilutions as a standard. Thus, gene level for each target mRNA was normalized against that of $\beta$-actin (Actb) for each sample. Both S100a8 and S100a9 mRNA were normalized against that of glyceraldehyde-3-phosphate dehydrogenase (Gapdh) in each sample. The following primers were used: S100a8, 5'-CCG TCT TCA AGA CAT CGT TTG A-3' and 5'-GTA GAG GGC ATG GTG ATT TCC T-3'; S100a9, 5'-GTC CAG GTC CTC CAT GAT GT-3' and 5'-GAA GGA AGG ACA CCC TGA CA-3'; Cebpa, 5'-CAA GAA GTC GGT GGA CAA GAA- $3^{\prime}$ and $5^{\prime}$-CGT TGC GTT GTT TGG CTT TA-3'; Csf $3 r, 5^{\prime}$-GGG ACC TCT TCA CCT ACT ACA- $3^{\prime}$ and $5^{\prime}$-CAG TCT ACC CAG ATG GTG TTA AG3'; Csf $31,5^{\prime}-\mathrm{TCC}$ TGC TTA AGT CCC TGG AG-3' and 5'-TGA CAC AGC TTG TAG GTG GC-3'; Actb, 5'-TTC TTT GCA GCT CCT TCG TT-3' and 5'-ATG GAG GGG AAT ACA GCC C-3'.

\section{Statistical analysis}

Data are expressed as the means \pm standard error of the mean (SEM). The significance of differences was analyzed using one-way ANOVA and Bonferroni test or Mann-Whitney $U$ test. $P<0.05$ was considered significantly different.

\section{Abbreviations}

CML, chronic myeloid leukemia; Tet, tetracycline; G-MDSC, granulocytic myeloid-derived suppressor cells; M-MDSC, monocytic myeloid-derived suppressor cells; IL$1 \beta$, interleukin- $1 \beta$; TNF- $\alpha$, tumor necrosis factor- $\alpha$; FRET, fluorescence resonance energy transfer; NLRP3, Nod-like receptor family, pyrin domain containing 3; SCAT1, a sensor of activated caspase-1 based on FRET; TG, transgenic; WT, wild-type; CHX, cycloheximide; WCL, whole cell lysate; G-CSF, granulocyte-colony stimulation factor; WST-8, [2-(2-methoxy-4-nitrophenyl)-3-(4-nitrophenyl)-5-(2,4disulfophenyl)-2H-tetrazolium, monosodium salt]; PI3K, phosphatidylinositol 3 kinase; STAT5, signal transducer and activator of transcription 5; PI, propidium iodide; PARP, poly ADP ribose polymerase; FLICA, fluorescently labelled inhibitor of caspases; ROS, reactive oxygen species; NF$\kappa \mathrm{B}$, nuclear factor- $\kappa \mathrm{B} ; \mathrm{C} / \mathrm{EBP} \alpha, \mathrm{CCAAT} /$ enhancer binding protein $\alpha$; PE, phycoerythrin; APC, allophycocyanin; FITC, fluorescein isothiocyanate

\section{Author contributions}

M.T. designed and performed experiments, analyzed and interpreted data, and wrote the manuscript; F.T. performed animal study, construction of BCR-ABL 
expression plasmids and reviewed the manuscript; T.M. performed flow cytometry, analyzed and interpreted data; K.I. performed immunofluorescence microscopy and reviewed the manuscript; M.Y. made the 32D/ TetOff-p210 cells; H.H. provided BCR-ABL transgenic mice and reviewed the manuscript; Y.M. designed, wrote and reviewed the manuscript.

\section{ACKNOWLEDGMENTS}

We thank Mr. Tsutomu Omori at Tokyo Women's Medical University for technical assistance. We thank Dr. Yoshifumi Yamaguchi and Dr. Masayuki Miura at the University of Tokyo for providing a plasmid construct (SCAT1/pcDNA3.1). We would like to thank Editage (www.editage.jp) for English language editing.

\section{CONFLICTS OF INTEREST}

All authors declare no conflicts of interest.

\section{FUNDING}

This work was supported by JSPS KAKENHI Grant Numbers JP24700987 (to MT), JP15K14411 (to MT), JP21117008 (to YM).

\section{REFERENCES}

1. Gishizky ML, Witte ON. Initiation of deregulated growth of multipotent progenitor cells by bcr-abl in vitro. Science. 1992; 256:836-9.

2. Maru Y. Molecular biology of chronic myeloid leukemia. Cancer Sci. 2012; 103:1601-10. https://doi.org/10.1111/j.1349-7006.2012.02346.x.

3. Deininger MW, Goldman JM, Melo JV. The molecular biology of chronic myeloid leukemia. Blood. 2000; 96:3343-56.

4. Ren R. Mechanisms of BCR-ABL in the pathogenesis of chronic myelogenous leukaemia. Nat Rev Cancer. 2005; $5: 172-83$.

5. Zhang B, Ho YW, Huang Q, Maeda T, Lin A, Lee SU, Hair A, Holyoake TL, Huettner C, Bhatia R. Altered microenvironmental regulation of leukemic and normal stem cells in chronic myelogenous leukemia. Cancer Cell. 2012; 21:577-92. https://doi.org/10.1016/j.ccr.2012.02.018.

6. Keller M, Ruegg A, Werner S Beer HD. Active caspase-1 is a regulator of unconventional protein secretion. Cell. 2008; 132:818-31. https://doi.org/10.1016/j.cell.2007.12.040.

7. Vande Walle L, Van Opdenbosch N, Jacques P, Fossoul A, Verheugen E, Vogel P, Beyaert R, Elewaut D, Kanneganti TD, van Loo G, Lamkanfi M. Negative regulation of the NLRP3 inflammasome by A20 protects against arthritis. Nature. 2014; 512:69-73. https://doi.org/10.1038/nature13322.
8. Croker BA, O’Donnell JA, Gerlic M. Pyroptotic death storms and cytopenia. Curr Opin Immunol. 2014; 26:12837. https://doi.org/10.1016/j.coi.2013.12.002.

9. Liu T, Yamaguchi Y, Shirasaki Y, Shikada K, Yamagishi M, Hoshino K, Kaisho T, Takemoto K, Suzuki T, Kuranaga E, Ohara O, Miura M. Single-cell imaging of caspase-1 dynamics reveals an all-or-none inflammasome signaling response. Cell Reports. 2014; 8:974-82. https://doi.org/10.1016/j.celrep.2014.07.012.

10. Greten TF, Mann MP, Korangy F. Myeloid derived suppressor cells in human diseases. Int Immunopharmacol. 2011; 11:802-7. https://doi.org/10.1016/j.intimp.2011.01.003.

11. Young MR, Newby M, Wepsic HT. Hematopoiesis and suppressor bone marrow cells in mice bearing large metastatic Lewis lung carcinoma tumors. Cancer Res. 1987; 47:100-5.

12. Christiansson L, Söderlund S, Svensson E, Mustjoki $\mathrm{S}$, Bengtsson M, Simonsson B, Olsson-Strömberg U, Loskog AS. Increased level of myeloid-derived suppressor cells, programmed death receptor ligand 1/programmed death receptor 1 , and soluble CD25 in Sokal high risk chronic myeloid leukemia. PLoS One. 2013; 8: e55818. https://doi.org/10.1371/journal.pone.0055818.

13. Alemà $\mathrm{S}$, Casalbore $\mathrm{P}$, Agostini $\mathrm{E}$, Tatò $\mathrm{F}$. Differentiation of PC12 phaeochromocytoma cells induced by v-src oncogene. Nature. 1985; 316:557-9.

14. Takemoto K, Nagai T, Miyawaki A, Miura M. Spatiotemporal activation of caspase revealed by indicator that is insensitive to environmental effects. J Cell Biol. 2003; 160:235-43. https://doi.org/10.1083/jcb.200207111.

15. Era T, Witte ON. Regulated expression of P210 Bcr-Abl during embryonic stem cell differentiation stimulates multipotential progenitor expansion and myeloid cell fate. Proc Natl Acad Sci USA. 2000; 97:1737-42.

16. Tsukahara F, Maru Y. Bag1 directly routes immature BCRABL for proteasomal degradation. Blood. 2010; 116:358292. https://doi.org/10.1182/blood-2009-10-249623.

17. Guchhait P, Tosi MF, Smith CW Chakaraborty A. The murine myeloid cell line 32Dcl3 as a model system for studying neutrophil functions. J Immunol Methods. 2003; 283:195-204.

18. Andreu EJ, Lledo E, Poch E, Ivorra C, Albero MP, Martínez-Climent JA, Montiel-Duarte C, Rifón J, Pérez-Calvo J, Arbona C, Prósper F, PérezRoger I. BCR-ABL induces the expression of Skp2 through the PI3K pathway to promote $\mathrm{p} 27 \mathrm{Kip} 1$ degradation and proliferation of chronic myelogenous leukemia cells. Cancer Res. 2005; 65:3264-72. https://doi.org/10.1158/0008-5472.CAN-04-1357.

19. Gesbert F, Griffin JD. Bcr/Abl activates transcription of the Bcl-X gene through STAT5. Blood. 2000; 96:2269-76.

20. Kerr JF, Wyllie AH, Currie AR. Apoptosis: a basic biological phenomenon with wide-ranging implication in tissue kinetics. Br J Cancer. 1972; 26:239-57. 
21. Golstein P, Kroemer G. Cell death by necrosis: towards a molecular definition. Trends Biochem Sci. 2007; 32:37-43. https://doi.org/10.1016/j.tibs.2006.11.001.

22. Doitsh G, Galloway NL, Geng X, Yang Z, Monroe KM, Zepeda O, Hunt PW, Hatano H, Sowinski S, Muñoz-Arias I, Greene WC. Cell death by pyroptosis drives CD4 T-cell depletion in HIV-1 infection. Nature. 2014; 505:509-14. https://doi.org/10.1038/nature12940.

23. Gallipoli P, Pellicano F, Morrison H, Laidlaw K, Allan EK, Bhatia R, Copland M, Jørgensen HG, Holyoake TL. Autocrine TNF- $\alpha$ production supports CML stem and progenitor cell survival and enhances their proliferation. Blood. 2013; 122:3335-9. https://doi.org/10.1182/blood-2013-02-485607.

24. Lamkanfi M. Emerging inflammasome effector mechanisms. Nat Rev Immunol. 2011; 11:213-20. https://doi.org/10.1038/nri2936.

25. Hiratsuka S, Watanabe A, Aburatani H, Maru Y. Tumormediated upregulation of chemoattractants and recruitment of myeloid cells predetermines lung metastasis. Nat Cell Biol. 2006; 8:1369-75. https://doi.org/10.1038/ncb1507.

26. Simard JC, Cesaro A, Chapeton-Montes J, Tardif M, Antoine F, Girard D, Tessier PA. S100A8 and S100A9 induce cytokine expression and regulate the NLRP3 inflammasome via ROS-dependent activation of $\mathrm{NF}-\kappa \mathrm{B}^{1}$. PLoS One. 2013; 8:e72138. https://doi.org/10.1371/journal.pone.0072138.

27. Honda H, Oda H, Suzuki T, Takahashi T, Witte ON, Ozawa K, Ishikawa T, Yazaki Y, Hirai H. Development of acute lymphoblastic leukemia and myeloproliferative disorder in transgenic mice expressing p210bcr/abl: a novel transgenic model for human Ph1-positive leukemias. Blood. 1998; 91:2067-75.

28. Edgeworth J, Gorman M, Bennett R, Freemont P, Hogg N. Identification of $\mathrm{p} 8,14$ as a highly abundant heterodimeric calcium binding protein complex of myeloid cells. J Biol Chem. 1991; 266:7706-13.

29. Steinman RA, Tweardy DJ. Granulocyte colony-stimulating factor receptor mRNA upregulation is an immediate early marker of myeloid differentiation and exhibits dysfunctional regulation in leukemic cells. Blood. 1994; 83:119-27.

30. Tkatch LS, Rubin KA, Ziegler SF, Tweardy DJ. Modulation of human G-CSF receptor mRNA and protein in normal and leukemic myeloid cells by G-CSF and retinoic acid. J Leukoc Biol. 1995; 57:964-71.

31. Perrotti D, Cesi V, Trotta R, Guerzoni C, Santilli G, Campbell K, Iervolino A, Condorelli F, GambacortiPasserini C, Caligiuri MA, Calabretta B. BCR-ABL suppresses $\mathrm{C} / \mathrm{EBP} \alpha$ expression through inhibitory action of hnRNP E2. Nat Genet. 2002; 30:48-58. https://doi.org/10.1038/ng791.

32. Schuster C, Forster K, Dierks H, Elsasser A, Behre G, Simon N, Danhauser-Riedl S, Hallek M, Warmuth M. The effects of Bcr-Abl on $\mathrm{C} / \mathrm{EBP}$ transcription-factor regulation and neutrophilic differentiation are reversed by the Abl kinase inhibitor imatinib mesylate. Blood. 2003; 101:655-63.

33. Wetzler M, Talpaz M, Van Etten RA, Hirsh-Ginsberg C, Beran M, Kurzrock R. Subcellular localization of Bcr, Abl, and Bcr-Abl proteins in normal and leukemic cells and correlation of expression with myeloid differentiation. J Clin Invest. 1993; 92:1925-39.

34. Lee J, Kim Y, Lim J, Kim M, Han K. G-CSF and GM-CSF concentrations and receptor expression in peripheral blood leukemic cells from patients with chronic myelogenous leukemia. Ann Clin Lab Sci. 2008; 38:331-7.

35. Fang G, Kim CN, Perkins CL, Ramadevi N, Winton E, Wittmann S, Bhalla KN. CGP57148B (STI-571) induces differentiation and apoptosis and sensitizes Bcr-Abl-positive human leukemia cells to apoptosis due to antileukemic drugs. Blood. 2000; 96:2246-53.

36. Giallongo C, Romano A, Parrinello NL, La Cava P, Brundo MV, Bramanti V, Stagno F, Vigneri P, Chiarenza A, Palumbo GA, Tibullo D, Di Raimondo F. Mesenchymal Stem Cells (MSC) regulate activation of granulocyte-like myeloid derived suppressor cells (G-MDSC) in chronic myeloid leukemia patients. PLoS One. 2016; 11:e158392. https://doi.org/10.1371/journal.pone.0158392.

37. Giallongo C, Parrinello N, Tibullo D, La Cava P, Romano A, Chiarenza A, Barbagallo I, Palumbo GA, Stagno F, Vigneri P, Di Raimondo F. Myeloid derived suppressor cells (MDSCs) are increased and exert immunosuppressive activity together with polymorphonuclear leukocytes (PMNs) in chronic myeloid leukemia patients. PLoS One. 2014; 9:e101848. https://doi.org/10.1371/journal.pone.0101848.

38. Christiansson L, Söderlund S, Mangsbo S, HjorthHansen H, Höglund M, Markevärn B, Richter J, Stenke L, Mustjoki S, Loskog A, Olsson-Strömberg U. The tyrosine kinase inhibitors imatinib and dasatinib reduce myeloid suppressor cells and release effector lymphocyte responses. Mol Cancer Ther. 2016; 14:1181-91. https://doi.org/10.1158/1535-7163.MCT-14-0849.

39. Kobayashi S, Kimura F, Ikeda T, Osawa Y, Torikai H, Kobayashi A, Sato K, Motoyoshi K. BCR-ABL promotes neutrophil differentiation in the chronic phase of chronic myeloid leukemia by downregulating c-Jun expression. Leukemia. 2009; 23:16227. https://doi.org/10.1038/leu.2009.74.

40. Sinha P, Okoro C, Foell D, Freeze HH, Ostrand-Rosenberg S, Srikrishna G. Proinflammatory S100 proteins regulate the accumulation of myeloid-derived suppressor cells. J Immunol. 2008; 181:4666-75.

41. Jacamo R, Chen Y, Wang Z, Ma W, Zhang M, Spaeth EL, Wang Y, Battula VL, Mak PY, Schallmoser K, Ruvolo P, Schober WD, Shpall EJ, et al. Reciprocal leukemiastroma VCAM-1/VLA-4-dependent activation of NF- $\mathrm{KB}$ mediates chemoresistance. Blood. 2014;123:2691-702. https://oi.org/10.1182/blood-2013-06-511527. 
42. Vigneri P, Wang JY. Induction of apoptosis in chronic myelogenous leukemia cells through nuclear entrapment of BCR-ABL tyrosine kinase. Nat Med. 2001; 7:228-34. https://doi.org/10.1038/84683.

43. Barnes DJ, Palaiologou D, Panousopoulou E, Schultheis B, Yong AS, Wong A, Pattacini L, Goldman JM, Melo JV. Bcr$\mathrm{Abl}$ expression levels determine the rate of development of resistance to imatinib mesylate in chronic myeloid leukemia. Cancer Res. 2005; 65:8912-9.

44. Fang B, Mai L, Li N, Song Y, Chunhua Zhao R. Imatinib plus granulocyte colony-stimulating factor in chronic myeloid leukemia patients who have achieved partial or complete cytogenetic response while on imatinib. Case Rep Oncol. 2011; 4:192-7. https://doi.org/10.1159/000327512. 